\section{(6) OPEN ACCESS}

\title{
Population attributable risks and costs of diabetogenic chemical exposures in the elderly
}

\author{
Leonardo Trasande, ${ }^{1,2,3,4}$ Erik Lampa, ${ }^{5}$ Lars Lind, ${ }^{6}$ P Monica Lind ${ }^{7}$
}

\begin{abstract}
${ }^{1}$ New York University (NYU) School of Medicine, New York, New York, USA

${ }^{2}$ NYU Wagner School of Public Service, New York, New York, USA

${ }^{3}$ Department of Nutrition, NYU Steinhardt School of Culture, Education and Human Development, Food \& Public Health, New York, New York, USA

${ }^{4} \mathrm{NYU}$ College of Global Public Health, New York University, New York, New York, USA ${ }^{5}$ Uppsala Clinical Research Center, Uppsala, Sweden ${ }^{6}$ Department of Medical Sciences, Cardiovascular Epidemiology, Uppsala University, Uppsala, Sweden ${ }^{7}$ Department of Medical Sciences, Occupational and Environmental Medicine, Uppsala University, Uppsala, Sweden
\end{abstract}

\section{Correspondence to} Dr Leonardo Trasande, Department of Pediatrics, New York University School of Medicine, 403 East 34th Street, New York, NY 10016, USA:

leonardo.trasande@nyumc.org

Received 27 June 2016 Revised 22 August 2016 Accepted 23 August 2016 Published Online First 26 October 2016

\section{ABSTRACT \\ Background A previous analysis examined the} contribution of endocrine disruptor exposures (endocrinedisrupting chemicals, EDCs) to adult diabetes, but was limited to effects of phthalates in middle-aged women and did not simultaneously examine multiple EDCs which are known to coexist in the environment. We therefore endeavoured to quantify potential reductions in diabetes and disease costs that could result from reducing synthetic chemical diabetogenic exposures in the elderly in Europe.

Methods We leveraged the Prospective Investigation of the Vasculature in Uppsala Seniors (PIVUS) study ( 1000 participants), which has measured exposure to phthalates; dichlorodiphenyltrichloroethylene; polychlorinated biphenyls (PCBs) and perfluoroalkyl substances to examine their independent contribution to diabetes. We estimated risk reductions assuming identical $25 \%$ reductions across levels of 4 selected compounds (PCB 153, monoethylphthalate, dichlorodiphenyldichloroethylene and perfluorononanoic acid), and diabetes costs saved in European men and women if diabetogenic exposures are limited.

Results Reduction of chemical exposures was associated with a $13 \%(95 \% \mathrm{Cl} 2 \%$ to $22 \%)$ reduction in prevalent diabetes, compared with $40 \%$ resulting from an identical $(25 \%)$ reduction in body mass index (BMI) in cross-sectional analyses. Extrapolating to Europe, 152481 cases of diabetes in Europe and $€ 4.51$ billion/year in associated costs could be prevented, compared with 469172 cases prevented by reducing BMI.

Conclusions These findings support regulatory and individual efforts to reduce chemical exposures to reduce the burden and costs of diabetes.

\section{INTRODUCTION}

Increasing evidence suggests that synthetic chemicals commonly found in the environment contribute to metabolic disorders, especially obesity and diabetes. ${ }^{1} 2$ Though diet and physical activity are the major contributors, chemical exposures can be regulated. The costs of safer alternatives to the diabetogenic and other metabolic disruptors can be compared with the health benefits of prevention. ${ }^{3}$

A recent report suggests that $€ 15$ billion in costs of new-onset, type 2 diabetes in older women are attributable to endocrine-disrupting chemicals (EDCs). ${ }^{4}$ This study leveraged the Nurses' Health Study which associated urinary phthalates with longitudinal increases in diabetes, controlling many relevant confounders. Though this study did control for another plausible diabetogen, bisphenol A, the study was unable to control for persistent organic pollutants that coexist and may have supra-additive effects. ${ }^{5}$

We therefore examined data from the Prospective Investigation of the Vasculature in Uppsala Seniors (PIVUS) study, which measured persistent and non-persistent chemical exposure to examine their independent contribution to diabetes. Previous publications have associated prevalent diabetes with polychlorinated biphenyls (PCBs), persistent chlorinated pesticides, phthalates and perfluoroalkyl substances (PFASs). ${ }^{6-9}$ Use of PIVUS also permits quantification of attributable burden in men as well as women, in whom exposures are likely to induce diabetes independent of sex steroid disruption, since the age is 70 years in all participants.

To compare risks with other common risks, we modelled identical 25\% percentage reductions in contaminant levels, as well as in body mass index (BMI). We also examined the aggregate reduction in risk produced by simultaneously reducing all four contaminants to assess an aggregate burden of diabetes that can be attributed to environmental contaminants. Finally, we leveraged cost-of-illness data to estimate the preventable cost of adult diabetes in Europeans.

\section{METHODS}

\section{Sample}

PIVUS is a population-based cohort derived from the individuals aged 70 living in the city of Uppsala, Sweden ( $\mathrm{n}=1016 ; 50 \%$ women). For full details, please see Lind et al. ${ }^{10}$ Prevalent diabetes was defined as antidiabetic therapy or fasting plasma glucose $\geq 7.0 \mathrm{mmol} / \mathrm{L} \quad(n=119)$. Fasting blood was drawn in the morning for the determination of 33 environmental contaminants. The following calculations were based on data previously presented regarding the risk of prevalent diabetes of different environmental contaminants. ${ }^{6-9}$ The present analyses use a cross-sectional design. Owing to randomly missing data for some of the contaminants, data from 953 of the participants were used in the calculations.

\section{Statistical methods}

Biomarkers were selected based on significance in multivariable, single-exposure models: plasma monoethylphthalate (MEP); serum dichlorodiphenyldichloroethylene ( $\left.p, p^{\prime}-\mathrm{DDE}\right)$; serum $2,2^{\prime}, 4$, 4',5,5'-hexachlorobiphenyl (PCB 153); and perfluorononanoic acid (PFNA). The analytical procedures have previously been given in detail (6-9). Poisson regression models were used as the bases for the calculations. Included as independent variables in the models were the four contaminants as well as sex, BMI, physical activity, daily energy

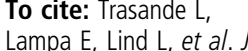
Epidemiol Community Health 2017:71:111-114. 
intake and daily alcohol intake. Population attributable fractions (PAFs) were calculated based on the attribrisk function in the R-package with the same name with two exceptions. Attribrisk uses logistic regression whereas we sought relative risk/prevalence ratio as the outcome could be considered common and an OR would not be a good approximation for the relative risk. Hence, Poisson regression was used instead, following published methods. ${ }^{11}$ To estimate PAFs, we first note that the estimated probability from the Poisson regression of being a case for any individual in the sample is

$$
\hat{\mathrm{P}}(\text { case })=\mathrm{e}^{\mathrm{X} \beta}
$$

where $\mathrm{X} \beta$ is the linear predictor resulting from the regression model. $X$ denotes the design matrix and $\beta$ is the vector of regression coefficient. Focusing on cases only, we can estimate the probability of being a case under a hypothetical scenario in which the exposure(s) are reduced by a certain amount given as

$$
\hat{\mathrm{P}}\left(\text { case }_{\text {hypothetical }} \mid \text { case }_{\text {observed }}\right)=\mathrm{e}^{\mathrm{X}_{\mathrm{c}} \beta}
$$

where $\mathrm{X}_{\mathrm{C}}$ is the contrast matrix obtained by subtracting the observed exposure(s) from the hypothetical. The sum of all predicted probabilities for the cases in the sample corresponds to the expected number of cases expected under the hypothetical scenario. The PAF is then calculated as

$$
\mathrm{PAF}=1-\frac{1}{\mathrm{~N}_{\text {cases }}} \sum_{\text {cases }} \mathrm{e}^{\gamma \mathrm{X}_{\mathrm{C}} \beta}
$$

where $\gamma$ is a shrinkage factor defined as

$$
\gamma=\frac{\operatorname{model} \chi^{2}-p}{\operatorname{model} \chi^{2}}
$$

where $\mathrm{p}$ is the total degrees of freedom and model $\chi^{2}$ is the likelihood ratio statistic for testing the joint influence of all variables in the model. ${ }^{12}$ As there were few cases of diabetes relative to the model degrees of freedom, the models may overfit. The shrinkage factor shrinks the PAF towards zero and was used to compensate for the overfitting when generalising the results to the European population.

Five models were developed with the difference between the models being the hypothetical scenarios. The first scenario assumed a simultaneous $25 \%$ decrease in all four contaminants while the remaining scenarios assumed a $25 \%$ decrease in a single contaminant while keeping the other contaminants constant. The bootstrap was used to construct $95 \%$ bias corrected and accelerated CIs for PAF using 10000 replicates. ${ }^{13}$ All analyses were made using R V.3.2.4 (R Core Team. R: A language and environment for statistical computing. R Foundation for Statistical Computing, Vienna, Austria. https://http://www. R-project.org/ 2016).

\section{Burden of disease and economic estimation}

The number of diabetes cases among 70-75 years old was estimated by multiplying age-standardised prevalence of diabetes in Europe $(6.5 \%)^{14}$ against the population estimate of $70-75$ years old. ${ }^{15}$ Annual cost estimates for diabetes per adult in 2010 were obtained from the analyses by Zhang et al, ${ }^{16}$ in US dollars. Given that prevalent diabetes results in costs over multiple years
Table 1 Biomarkers of exposure in the Prospective Investigation of the Vasculature in Uppsala Seniors

\begin{tabular}{lllll}
\hline Biomarker & N & Median & 25th centile & 75th centile \\
\hline MEP (ng/mL) & 963 & 11.70 & 7.22 & 17.50 \\
$p, p^{\prime}$-DDE (ng/g lipid) & 953 & 1858 & 1024 & 3415 \\
PCB 153 (ng/g lipid) & 953 & 1427 & 1111 & 1843 \\
PFNA (ng/mL) & 965 & 0.71 & 0.53 & 0.97
\end{tabular}

MEP, urinary monoethylphthalate; PCB 153 , serum $2,2^{\prime}, 4,4^{\prime}, 5,5^{\prime}$-hexachlorobiphenyl; PFNA, perfluorononanoic acid; $p, p^{\prime}$-DDE, serum dichlorodiphenyldichloroethylene.

of each subsequent lifetime, annual costs were aggregated over a 10 -year period, using 3\% discounting.

\section{Human participants}

PIVUS was approved by the Ethics Committee of the University of Uppsala and the participants gave informed consent. LT signed a New York University School of Medicine Institutional Review Board attestation form documenting the nature of his involvement as non-human participants research.

\section{RESULTS}

Table 1 presents descriptive biomarker data analysed in relation to diabetes, documenting exposures similar to those identified in other European populations. All four exposures taken singly had near-significant prevalence ratios (table 2), though reduction of all four exposures by $25 \%$ was associated with a $13 \%(95 \%$ CI $2 \%$ to $22 \%$ ) lower prevalence of diabetes, compared with a $40 \%$ reduction in diabetes prevalence in association with an identical (25\%) reduction in BMI. Extrapolation to Europe suggests that 152481 cases of diabetes could be prevented by reducing EDC exposure, compared with 469172 produced by a population-wide $25 \%$ reduction in BMI (table 3). Economic benefits of reducing EDC-attributable diabetes were estimated to be $€ 4.51$ billion/year compared with the $€ 13.9$ billion benefits of reducing BMI.

\section{DISCUSSION}

The present study confirms substantial contribution, especially of mixtures of EDCs, to adult type 2 diabetes, and large annual costs of medical care. ${ }^{4}$ While some will question extrapolation on limited data, our findings regarding chemical diabetogens are not unique and have also been found by several other research groups. ${ }^{5}$ 17-22 These epidemiological findings are likely to be causal, since they are in line with experimental mechanistic data. ${ }^{23-32}$

All the same, we acknowledge that residual confounding may have resulted in effect overestimation for the chemical exposures studied. The calculated PAFs may not apply to older age ranges

Table 2 Population attributable risk in multiexposure models

\begin{tabular}{ll}
\hline Biomarker & PAF $(95 \% \mathrm{CI})$ \\
\hline All four chemical exposures & $0.13(0.02$ to 0.22$)$ \\
MEP & $0.01(-0.02$ to 0.05$)$ \\
PCB 153 & $0.02(-0.02$ to 0.06$)$ \\
$p, p^{\prime}-$ DDE & $0.06(-0.05$ to 0.15$)$ \\
PFNA & $0.06(-0.02$ to 0.13$)$ \\
BMI & $0.40(0.16$ to 0.53$)$
\end{tabular}

PAFs assume $25 \%$ reduction in each risk factor.

$\mathrm{BMI}$, body mass index; MEP, urinary monoethylphthalate; PAF, population attributable

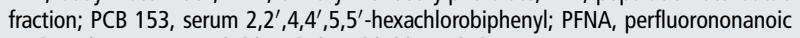
acid; $p, p^{\prime}-\mathrm{DDE}$, serum dichlorodiphenyldichloroethylene. 
Table 3 Attributable disease and cost estimates

\begin{tabular}{lll}
\hline Risk factor & $\begin{array}{l}\text { Body mass } \\
\text { index }\end{array}$ & $\begin{array}{l}\text { Endocrine-disrupting } \\
\text { chemical exposures }\end{array}$ \\
\hline $\begin{array}{l}\text { European population, } \\
70-75 \text { years old }\end{array}$ & 18045093 & \\
$\begin{array}{l}\text { Diabetes prevalence } \\
\text { Prevalent diabetes, Europe }\end{array}$ & $6.5 \%$ & \\
Preventable cases & 1172931 & \\
Cost/case & 469172 & 152481 \\
Preventable costs & $€ 29585$ & \\
\hline
\end{tabular}

insofar as biomarker levels have decreased ecologically. Exposures much earlier than study entry may have contributed to those measured in biomarkers at study entry.

It should be emphasised that PCBs have already been banned, under the Stockholm Convention. ${ }^{33} 34$ The pesticide dichlorodiphenyltrichloroethylene, for which the measured levels of $p$, $p^{\prime}$-DDE are proxy, has also been banned, except for the eradication of malaria in some parts of southern Africa. Long-chain perfluoroalkyl compounds, including PFNA, have completed a voluntary phase-out in the USA, though the expected reductions in serum PFNA have not been identified. ${ }^{35} 36$

Yet, healthcare providers can advise patients to reduce their exposure to diabetogenic contaminants identified in this study. Choosing personal care products labelled as 'phthalate free' has reduced urinary levels of MEP by $27 \%$ in young girls in one study. ${ }^{37}$ Other phthalates known to be metabolic disruptors are known food contaminants, and a fresh food intervention has produced even larger reductions in exposure. ${ }^{38}$ Short-chain PFASs contaminate food through packaging and contact surfaces, and are increasingly found in food. ${ }^{39}$ Consumption of a diet according to WHO recommendations has been associated with lower levels of PFASs and PCBs. ${ }^{40} 41$

Our findings also speak the need for a strong regulatory framework that proactively identifies chemical hazards before they are widely used, and the use of safer alternatives. The European Union is actively considering regulations to limit such exposures, ${ }^{4}$ and the USA recently revised the Toxic Substances Control Act, ${ }^{42}$ but does not consider endocrine disruption. In the absence of such a framework, newly developed synthetic chemicals may emerge as diabetogenic exposures, replacing banned or substituted hazards as contributors.

\section{CONCLUSIONS}

Environmental contaminants contribute substantially to diabetes in the elderly, with costs in Europe likely to be in billions of Euros.

\section{What is already known on this subject}

Increasing evidence suggests that synthetic chemicals commonly found in the environment contribute to metabolic disorders, especially obesity and diabetes. Yet, only one study has quantified attributable disease and costs, did not examine mixtures of chemicals which may have synergistic effects and was limited to effects in middle-aged women.

\section{What this study adds}

Reduction of chemical exposures was associated with a $13 \%$ (95\% Cl $2 \%$ to $22 \%$ ) reduction in diabetes in the elderly, preventing 152481 cases of diabetes in Europe and €4.51 billion/year in associated costs. These findings support regulatory and individual efforts to reduce chemical exposures.

Twitter Follow Leonardo Trasande at @leotrasande

Contributors LT wrote the manuscript, and performed economic analyses. PML and LL provided primary study access and reviewed/edited the manuscript. EL performed statistical analyses. LT and PML are the joint guarantors of this work, including the study design, access to data, and the decision to submit and publish the manuscript.

Competing interests None declared.

Provenance and peer review Not commissioned; externally peer reviewed.

Open Access This is an Open Access article distributed in accordance with the Creative Commons Attribution Non Commercial (CC BY-NC 4.0) license, which permits others to distribute, remix, adapt, build upon this work non-commercially, and license their derivative works on different terms, provided the original work is properly cited and the use is non-commercial. See: http://creativecommons.org/ licenses/by-nc/4.0/

\section{REFERENCES}

1 Hauser R, Skakkebaek NE, Hass U, et al. Male reproductive disorders, diseases, and costs of exposure to endocrine-disrupting chemicals in the European union. $J$ Clin Endocrinol Metab 2015;100:1267-77.

2 Lind L, Lind PM, Lejonklou MH, et al. Uppsala consensus statement on environmental contaminants and the global obesity epidemic. Environ Health Perspect 2016;124:A81-3.

3 Trasande L, Massey RI, DiGangi J, et al. How developing nations can protect children from hazardous chemical exposures while sustaining economic growth. Health Aff (Millwood) 2011;30:2400-9.

4 Trasande L, Zoeller RT, Hass U, et al. Estimating burden and disease costs of exposure to endocrine-disrupting chemicals in the European Union. J Clin Endocrinol Metab 2015;100:1245-55.

5 Sun Q, Cornelis MC, Townsend MK, et al. Association of urinary concentrations of bisphenol $A$ and phthalate metabolites with risk of type 2 diabetes: a prospective investigation in the Nurses' Health Study (NHS) and NHSII cohorts. Environ Health Perspect 2014;122:616-23.

6 Lind L, Lind PM. Can persistent organic pollutants and plastic-associated chemicals cause cardiovascular disease? J Intern Med 2012;271:537-53.

7 Lind L, Zethelius B, Salihovic S, et al. Circulating levels of perfluoroalkyl substances and prevalent diabetes in the elderly. Diabetologia 2014;57:473-9.

8 Lind PM, Zethelius B, Lind L. Circulating levels of phthalate metabolites are associated with prevalent diabetes in the elderly. Diabetes Care 2012;35:1519-24.

9 Lee DH, Lind PM, Jacobs DR Jr, et al. Polychlorinated biphenyls and organochlorine pesticides in plasma predict development of type 2 diabetes in the elderly: the prospective investigation of the vasculature in Uppsala Seniors (PIVUS) study. Diabetes Care 2011;34:1778-84.

10 Lind L, Fors N, Hall J, et al. A comparison of three different methods to evaluate endothelium-dependent vasodilation in the elderly: the Prospective Investigation of the Vasculature in Uppsala Seniors (PIVUS) study. Arterioscler Thromb Vasc Biol 2005;25:2368-75.

11 Zou G. A modified Poisson regression approach to prospective studies with binary data. Am J Epidemiol 2004;159:702-6.

12 Harrell JF. Regression modeling strategies. With applications to linear models, logistic and ordinal regression, and survival analysis. Springer Series in Statistics, 2015. ISBN: 978-3319194240.

13 Efron B, Tibshirani RJ. An introduction to the bootstrap. Chapman \& Hall/CRC, 1993. ISBN: 0-412-04231-2.

14 European Commission. Prevalence estimates of diabetes, adults aged 20-79 years, 2010. Chapter 1.14.1 in Health at a Glance: Europe 2010. http://ec.europa.eu/ health/reports/docs/health_glance_en.pdf (accessed 31 May 2016).

15 United Nations Economic Commission for Europe. Population, 5-year age groups, by sex. 2014. http://w3.unece.org/pxweb/Dialog/varval.asp?ma=001_GEPOAGESEX_ REG_r\&ti=Population $\% 2 \mathrm{C}+5$-year+age+groups $\% 2 \mathrm{C}+$ by + Age $\% 2 \mathrm{C}+\mathrm{Sex} \% 2 \mathrm{C}$ + Country+and+Year\&path=../DATABASE/Stat/30-GE/01-Pop/\&lang=1 (accessed 26 Aug 2014). 
16 Zhang P, Zhang $X$, Brown J, et al. Global healthcare expenditure on diabetes for 2010 and 2030. Diabetes Res Clin Pract 2010;87:293-301.

17 Lee DH, Lee IK, Song K, et al. A strong dose-response relation between serum concentrations of persistent organic pollutants and diabetes: results from the National Health and Examination Survey 1999-2002. Diabetes Care 2006;29:1638-44.

18 Rignell-Hydbom A, Lidfeldt J, Kiviranta $H$, et al. Exposure to $p, p^{\prime}-D D E$ : a risk factor for type 2 diabetes. PLOS ONE 2009;4:e7503.

19 Longnecker MP, Michalek JE. Serum dioxin level in relation to diabetes mellitus among air force veterans with background levels of exposure. Epidemiology 2000;11:44.

20 Turyk M, Anderson H, Knobeloch L, et al. Organochlorine exposure and incidence of diabetes in a cohort of Great Lakes sport fish consumers. Environ Health Perspect 2009;117:1076-82.

21 Svensson K, Hernández-Ramírez RU, Burguete-García A, et al. Phthalate exposure associated with self-reported diabetes among Mexican women. Environ Res 2011;111:792-6.

22 Su TC, Kuo CC, Hwang JJ, et al. Serum perfluorinated chemicals, glucose homeostasis and the risk of diabetes in working-aged Taiwanese adults. Environ Int 2016;88:15-22.

23 Wilson VS, Blystone $C R$, Hotchkiss AK, et al. Diverse mechanisms of anti-androgen action: impact on male rat reproductive tract development. Int I Androl 2008;31:178-87.

24 Shekhar PV, Werdell J, Basrur VS. Environmental estrogen stimulation of growth and estrogen receptor function in preneoplastic and cancerous human breast cell lines. J Natl Cancer Inst 1997;89:1774-82.

25 Moreno-Aliaga MJ, Matsumura F. Effects of 1,1,1-trichloro-2,2-bis ( $p$-chlorophenyl)-ethane ( $p, p^{\prime}-\mathrm{DDT}$ ) on 3T3-L1 and 3T3-F442A adipocyte differentiation. Biochem Pharmacol 2002;63:997-1007.

26 Desvergne B, Feige JN, Casals-Casas C. PPAR-mediated activity of phthalates: a link to the obesity epidemic? Mol Cell Endocrinol 2009;304:43-8.

27 Jepsen KF, Abildtrup A, Larsen ST. Monophthalates promote IL-6 and IL-8 production in the human epithelial cell line A549. Toxicol In Vitro 2004;18:265-9.

28 Gourlay T, Samartzis I, Stefanou D, et al. Inflammatory response of rat and human neutrophils exposed to di-(2-ethyl-hexyl)-phthalate-plasticized polyvinyl chloride. Artif Organs 2003;27:256-60.

29 Henriksen EJ, Diamond-Stanic MK, Marchionne EM. Oxidative stress and the etiology of insulin resistance and type 2 diabetes. Free Radic Biol Med 2011;51:993-9.
30 Herbstman JB, Sjödin A, Apelberg BJ, et al. Birth determinants of prenatal exposure to polychlorinated biphenyl (PCBS) and polybrominated diphenyl ethers (PBDE) in an urban population. Environ Health Perspect 2007;115:1794-800.

31 Herbstman JB, Sjödin A, Apelberg BJ, et al. Birth delivery mode modifies the associations between prenatal polychlorinated biphenyl (PCB) and polybrominated diphenyl ether (PBDE) and neonatal thyroid hormone levels. Environ Health Perspect 2008;116:1376

32 Korashy HM, El-Kadi AO. The role of aryl hydrocarbon receptor in the pathogenesis of cardiovascular diseases. Drug Metab Rev 2006;38:411-50.

33 Porta M, Zumeta E. Implementing the Stockholm treaty on persistent organic pollutants. Occup Environ Med 2002;59:651-2.

34 Valvi D, Mendez MA, Garcia-Esteban R, et al. Prenatal exposure to persistent organic pollutants and rapid weight gain and overweight in infancy. Obesity (Silver Spring) 2014;22:488-96

35 Calafat AM, Wong LY, Kuklenyik Z, et al. Polyfluoroalkyl chemicals in the U.S. population: data from the National Health and Nutrition Examination Survey (NHANES) 2003-2004 and comparisons with NHANES 1999-2000. Environ Health Perspect 2007;115:1596-602.

36 Ode $\mathrm{A}$, Rylander $\mathrm{L}$, Lindh $\mathrm{CH}$, et al. Determinants of maternal and fetal exposure and temporal trends of perfluorinated compounds. Environ Sci Pollut Res Int 2013;20:7970-8.

37 Harley KG, Kogut K, Madrigal DS, et al. Reducing phthalate, paraben, and phenol exposure from personal care products in adolescent girls: findings from the hermosa intervention study. Environ Health Perspect 2016; doi:10.1289/ehp.1510514

38 Rudel RA, Gray JM, Engel CL, et al. Food packaging and bisphenol A and bis (2-ethyhexyl) phthalate exposure: findings from a dietary intervention. Environ Health Perspect 2011;119:914-20.

39 Glynn A, Berger U, Bignert A, et al. Perfluorinated alkyl acids in blood serum from primiparous women in Sweden: serial sampling during pregnancy and nursing, and temporal trends 1996-2010. Environ Sci Technol 2012;46:9071-9.

40 Ax E, Lampa E, Lind L, et al. Circulating levels of environmental contaminants are associated with dietary patterns in older adults. Environ Int 2015;75:93-102.

41 Sjogren P, Montse R, Lampa E, et al. Circulating levels of perfluoroalkyl substances are associated with dietary patterns-a cross sectional study in elderly Swedish men and women. Environ Res 2016;150:59-65.

42 Trasande L. Updating the toxic substances control act to protect human health. JAMA 2016;315:1565-6. 